\title{
Safe Injection Practice (Safe-1 Program)
}

\author{
T U SUKUMARAN
}

National President IAP, Sreeshylam, Ettumanoor P.O., Kottayam-686631; Professor of Peadiatrics, PIMS, Tiruvalla, India. tusukumaran@gmail.com

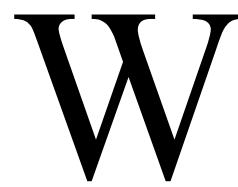
HO defines Safe Injection, as an injection that does no harm to recipients; does not expose the health care worker to any risk; and does not result in waste that is dangerous for the community. In India, 300 crore injections are given in an year out of which 180 crore are unsafe; diseases transmitted through unsafe injection practices include hepatitis B: 21 million, hepatitis C: 2 million, and HIV-AIDS: 3 lakhs per year. Safe-I is a joint initiative of Indian Academy of Pediatrics (IAP) and Becton Dickison, India aimed at ensuring safety of the healthcare workers by safe biomedical waste management.

\section{Objectives of the Project}

1. Implement Safe-I project: safe injection practices; safe infusion practices; infection control; safe waste management; and safety of the health care worker.

2. Formation of Infection Control Committee in all the hospitals.

3. Written protocols for: safe injection; safe infusion; surveillance for hospitals acquired infection; needle stick injury protocol; and post exposure prophylaxis policies.

4. Vaccination for all healthcare workers for hepatitis B.

5. Policy for segregation and disposal of biomedical waste management.

6. Appointment of infection control nurse/doctor in all hospitals.

\section{IAP Modules for Safe Injection Practice}

The concept of Safe Injection Practice was conceived by IAP in 2004 and the national consensus meeting was held in 2005. Training modules and manuals were finalized [1] and more than 30

\section{Protocols for SAFe InJeCtions}

1. Written protocols on injection safety are available in the hospital.

2. PEP policy prepared on blood exposure and made available to all staff members.

3. Charts on Do's and Don'ts made and displayed all across the hospital wherever injections are delivered.

4. Training should be done on a continuous and regular manner.

(a) All nurses (new and old) are regularly updated on injection safety every 6 months

(b) All doctors practicing in the hospital are oriented at least once a year on injection safety

(c) All new recruits should immediately go through a course on injection safety

5. All healthcare workers and hospital staff should be vaccinated against hepatitis $B$.

6. Hospitals should ensure usage of only auto-disabled syringes for immunization and syringes with Re-use prevention feature for the curative injections.

7. All sharps generated in the hospital should be disposed in a sharps container (NIOSH guidelines) or disposed by using a hub cutter.

A team of experts visit those hospitals who achieves all these criteria and certifies the hospital as Safe-I Hospital.

workshops were organized. IAP continued this activity in 2006 with 30 more workshops. This year we are planning to revise the module and to conduct a new TOT followed by 30 workshops through out the country. I thank Dr S S Kamath, the National Coordinator of this program and Becton Dickison, India Pvt. Ltd., for the scientific grant for this project.

\section{REFERENCE}

1. Kamath SS, Bhave SY, Shah RC, Ugra D. IAP Guide Book on Safe Injection Practice, 2nd Edition. Mumbai: Indian Academy of Pediatrics; 2006.p.13-5. 